\title{
Caught in lead recall limbo
}

$\mathrm{F}$ ive years after the recall of faulty defibrillator leads that were found to deliver random and potentially deadly shocks to patients, Canadians are still being exposed to increasing risk of injury and death, while clinicians are scrambling to determine whether it's best to remove the devices.

In 2007, medical device manufacturer Medtronic Inc., based in Minneapolis, Minnesota, issued a global voluntary recall of its Sprint Fidelis leads because the wires, which are implanted in the heart and attached to a patient's defibrillator to monitor and correct arrhythmia, were prone to fracture resulting in inappropriate shocks (wwwp.medtronic.com /Newsroom/NewsReleaseDetails.do?ite $\mathrm{mId}=1192213397218 \&$ format=pdf\&lang =en_US). While recalling the leads, Medtronic claimed the overall risk to patients was not "statistically significant" and recommended against prophylactic replacement.

But a class-action lawsuit, certified in Ontario on behalf of the more than 6000 Canadians implanted with the recalled leads, alleges that Medtronic "manufactured and sold defective electronic wires known as 'Leads,' which are an operative part of implantable heart defibrillators. It is alleged that the Leads were prone to fracture causing the defibrillators to malfunction. It is alleged that the failure rate is accelerating. The Plaintiffs allege that the Defendants conspired to conceal the defect from regulators and that they failed to warn doctors and the persons implanted with heart defibrillators," (www.kimorr.ca/PDF/Robinson v_Medtronic_certification_decision.pdf).

There was a lag of about a year between the time reports first began surfacing about lead failures to the time Medtronic issued what was essentially a voluntary product recall, alleges Victoria Paris, a lawyer with Kim Orr, the Toronto, Ontario-based law firm that launched the class action suit. "The company should have acted sooner."

In granting certification, Mr. Justice

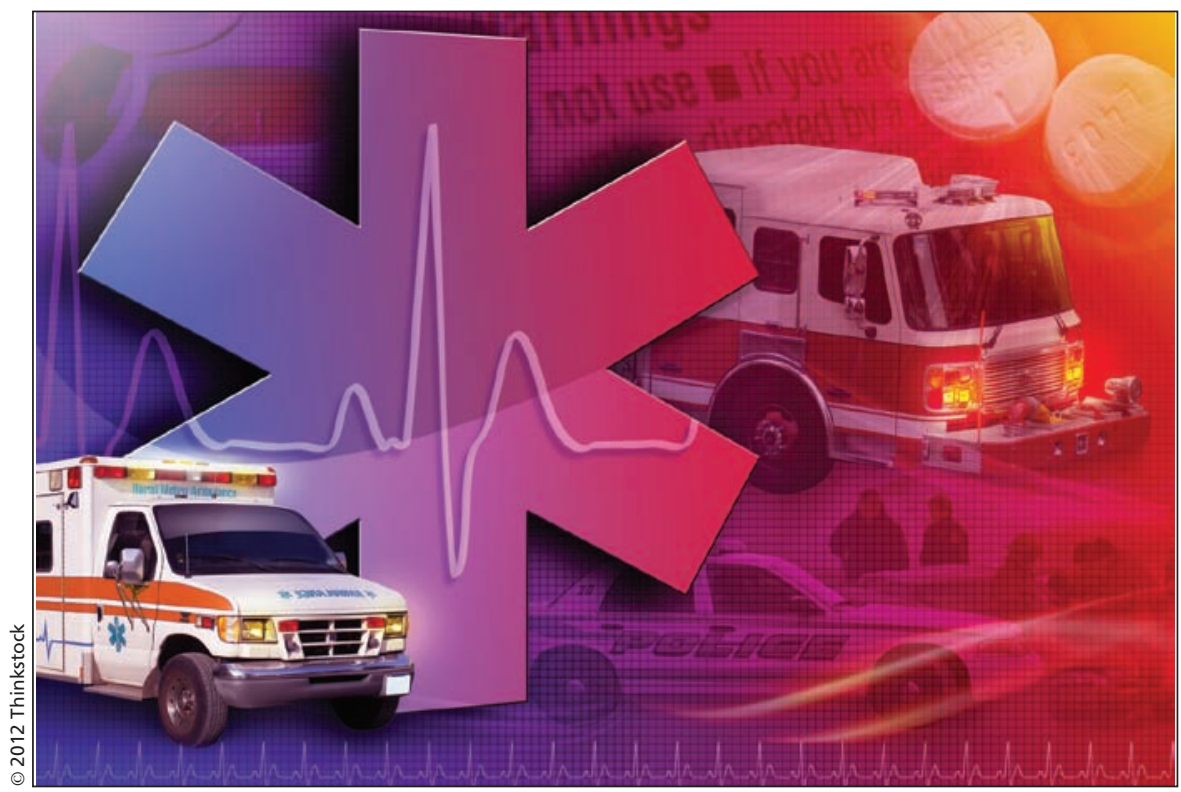

It's not clear exactly how many patients have experienced adverse events from fractured defibrillator leads.

Paul M. Perrell of the Ontario Superior Court of Justice noted that "Medtronic denies the Plaintiffs' allegations and intends to vigorous defend its reputation and the action. Its position is that it was not negligent in the manufacturing and distribution of the Leads and that it responded responsibly to the information provided to it about the performance of its product. It denies any conspiracy."

Meanwhile, cardiologists appear locked in a battle for consensus over how best to manage patients with implanted Fidelis leads, particularly as the risk of fracture accelerates with device age.

"We're really struggling to provide the best care we can for patients. The whole field of defibrillator therapy is in turmoil right now because of the major issues we're having with these leads," says Dr. Jamil Bashir, a cardiac surgeon at St. Paul's Hospital in Vancouver, British Columbia.

Although it's not clear exactly how many patients have experienced adverse events from the fractures, the University of Ottawa Heart Institute in Ontario has already replaced some 500 leads, says
Dr. David Birnie, director of the institute's Arrhythmia Device Clinic.

The rate of Fidelis lead failure increases over time, with failures approaching $17 \%$ just five years after implantation, according to a report of the Canadian Heart Rhythm Society Device Committee (Circulation 2012; Feb. 6 [Epub ahead of print]).

Surgeons at some major centres, such as Bashir, say they are removing the leads wherever possible. But he stresses it's not a decision to be taken lightly and across the country, doctors appear divided over whether the dangers of leaving the leads in patients outweigh the potential complications of replacing them, which include death, tears in a patient's heart, respiratory arrest, anesthesia complications and infection.

The Canadian Heart Rhythm Society Device Committee's report recommends that clinicians "strongly consider" lead replacement at the same time that they are replacing a defibrillator generator.

It's a sea change for the society, Bashir says.

But replacing a lead doesn't necessarily mean extraction, Birnie says. "In most 
cases, it means addition of a new lead and abandonment of the Fidelis. It's remarkable how many leads patients can tolerate and very rarely run into problems."

Other centres have opted to remotely monitor the leads, he adds. Hospitals can now receive electronic alerts that a lead failure is imminent a few hours or even days before it occurs, reducing the chance of inappropriate shock "from $50 \%$ to somewhere between $15 \%$ and $30 \%$."

"In retrospect, we jumped far too quickly to use new technology without the technology being assessed fully," or having a clear idea of how to handle possible recalls, Birnie adds.

Bashir concurs, arguing that a new international standard for defibrillator leads that is in the offing will mean a "whole new complex stage of transitioning to another version of the technology" at the time many implanters are reverting to older, more reliable leads out of concern over patient safety.

"It's not just Sprint Fidelis," Birnie says. "There are lots of problems with all the leads, some relating to the fact it's an extremely complex technology and you're asking it to do a lot, but there are also regulatory issues with respect to the way the leads are being released. ... I feel strongly we should move more slowly. I want to see decent clinical trials over a decent period of time to prove these new leads work."

Patients, meanwhile, are left to deal with the physical and emotional toll of a nonlethal failure of the leads. Some patients can experience upwards of 100 shocks in rapid succession, in addition to significant and persistent symptoms of anxiety, Birnie adds.

Lawyers in the class-action suit say they're also curious about whether Health Canada conducted an independent analysis on the safety of the leads. "Often what happens is ... Health Canada will look at approvals taken place in the United States and take that into consideration when approving a product in Canada," Paris says.

That can be problematic in cases in which a company skirts testing requirements by making minor modifications to existing products, she adds. "By going through that process, the leads were never properly evaluated or tested in the way they should be."
Paris also alleges that Medtronic knew about the Fidelis failures as early as 2005, but chose to ramp up its marketing efforts until recalling the products in late 2007. "At the time the leads were recalled, there were somewhere around 268000 leads implanted [worldwide]. That's a big difference from the 93000 a year and half prior when the problems first came to light."

Representative plaintiffs Sherry Marie Robinson and Dan Austen explained to the Ontario Superior Court of Justice in 2009 that they would not have had the Fidelis leads implanted in that period, had they known the wires were defective.

The suit seeks $\$ 800$ million in compensation or damages equal to the gross revenue or net income derived from sale of the leads. Medtronic denies all allegations of wrongdoing and intends to "vigorously defend" its actions, according to a written statement provided to CMAJ. The company states it acted "in the best interest of patients." — Lauren Vogel, CMAJ

CMAJ 2012. DOI:10.1503/cmaj.109-4155 